\title{
Aspectos gerais e silviculturais de Cordia americana, Aspidosperma polyneuron, Toona ciliata e Khaya spp.
}

General and silvicultura aspects of Cordia americana, Aspidosperma polyneuron, Toona ciliata e Khaya spp.

\section{Danieli Regina Klein ${ }^{1 *}$, Mariane Moura Andrade ${ }^{3}$, Joseane Aparecida Derengoski ${ }^{2}$, Edilaine Duarte ${ }^{1}$, Sandra Mara Krefta ${ }^{1}$, Ana Cláudia da Silveira ${ }^{1}$ e Eleandro José Brun ${ }^{3}$}

Recebido em 18/10/2015 / Aceito em 28/03/2016

\section{RESUMO}

O Brasil possui grande diversidade de espécies florestais, no entanto, os povoamentos em sua maioria são com espécies dos gêneros Eucalyptus e Pinus. Frente a isso, o presente estudo baseiase na análise das características de espécies nativas com alto potencial madeireiro e espécies de caráter inovador para cultivo. O cedro australiano (Toona ciliata) e o mogno africano (Khaya spp.) constituem espécies importantes, principalmente, beneficiando na redução da exploração das matas nativas ainda existentes no país. Entretanto as espécies de guajuvira (Cordia americana) e peroba-rosa (Aspidosperma polyneuron) mostram-se com um grande potencial ainda a ser explorado, tanto para liberação de plantios comerciais e seu uso adequado, que atenda exigências de sustentabilidade.

PALAVRAS-CHAVE: silvicultura, cultivo, espécies nativas.

\footnotetext{
ABSTRACT

Brazil has a great diversity of forest species; however, the stands contain mostly species of Eucalyptus and Pinus. Faced with this, the present study is based on the analysis of the characteristics of native species with high potential and innovative character of timber species for cultivation. The Australian cedar (Toona ciliata) and African mahogany (Khaya spp.) are important species, mainly benefiting in reducing the exploitation of native forests remaining in the country. However, the species of (Cordia Americana) and (Aspidosperma polyneuron) show great potential yet to be explored, both in releasing

${ }^{1}$ Universidade do Estado de Santa Catarina, Lages, SC, Brasil.

${ }^{2}$ Universidade Tecnológica Federal do Paraná, Pato Branco, PR, Brasil.

${ }^{3}$ Universidade Tecnológica Federal do Paraná, Dois Vizinhos, PR, Brasil.

*Autor para correspondência < drkleinn@gmail.com>
}

commercial plantations and their proper use, that meets sustainability requirements.

KEYWORDS: forestry, cultivation, native species.

\section{INTRODUÇÃO}

O Brasil possui uma grande diversidade de espécies florestais, entretanto, em seu território, os reflorestamentos existentes são, principalmente, de espécies exóticas, dos quais se destacam os gêneros Eucalyptus e Pinus, sendo que, as pesquisas e trabalhos focam, quase que exclusivamente, nestes gêneros. Desta forma, limita-se os estudos a poucos grupos e gêneros, resultando em uma carência de informações sobre demais espécies (FRANCK FILHO 2005).

Evidencia-se que estudos referentes às espécies nativas tratam apenas sobre suas características botânicas e dendrológicas. São poucos os estudos que mencionam as características silviculturais das espécies, principalmente em relação a seu crescimento, incremento e necessidade nutricional (GARRIDO 1981). Espécies nativas têm ritmos de crescimento e necessidades ecológicas diferentes nos diversos estágios de seu desenvolvimento.

As informações silviculturais a respeito de espécies nativas com potencial para o mercado produtor são escassas, assim como, alternativas às espécies nobres, que possuam características semelhantes, assegurando a qualidade no produto final. ZIECH (2008) citou o cedro-australiano como uma opção ao uso do mogno e cedro, por exemplo. Assim, estudos voltados ao desenvolvimento de técnicas de manejo florestal e o incentivo ao cultivo dessas espécies, preferencialmente aquelas com maior potencial para atender a indústria, são de ampla 
importância para o setor florestal.

Com base nas informações apresentadas, o presente estudo teve por objetivo caracterizar, a partir de uma revisão bibliográfica, espécies que possuem potencial para a utilização em fins madeireiros.

\section{DESENVOLVIMENTO}

\section{Toona ciliata M. Roem}

A espécie Toona ciliata M. Roem conhecida popularmente por cedro-australiano ou cedro vermelho, pertence a família Meliaceae, subfamília Swietenioideae e Tribo Cedreleae (BYGRAVE \& BYGRAVE 2005).

A área de ocorrência natural encontra-se entre os paralelos $15^{\circ}$ e $25^{\circ} \mathrm{N}$, compreendendo os países Índia, Bangladesh, Birmânia, Tailândia, China Meridional, Indonésia, Malásia e Filipinas e parte da Austrália, sendo encontrada em locais com até $1500 \mathrm{~m}$ de altitude, precipitação média anual entre 800 e 1800 $\mathrm{mm}$ e temperatura entre 20 e $26{ }^{\circ} \mathrm{C}$ (LAMPRECHT 1990).

Em seu bioma original, a espécie apresenta grande porte, podendo atingir 50 metros de altura e até 2 metros de diâmetro na altura do peito. Seu tronco é cilíndrico e retilíneo, podendo apresentar bifurcações. A casca é dura e grossa, com deiscência em placas retangulares e escamiformes, tendo coloração cinzamarrom com presença de líquens (PINHEIRO et al. 2006).

Suas folhas são alternas, compostas, imparipinadas e pendentes, Toona ciliata é monóica, geralmente apresenta flores masculinas e femininas na mesma inflorescência, sendo que esta é composta por três flores, duas laterais masculinas e a do meio feminina (STYLES 1972). A espécie é alógama, ocorrendo fecundação cruzada, devido as flores masculinas e femininas não abrirem ao mesmo tempo (PINHEIRO et al. 2003).

A espécie tem sua floração ocorrendo nos meses de setembro a novembro, com frutos de janeiro a março (SOUZA et al. 2010). O fruto é cápsula deiscentes com 15 a $20 \mathrm{~mm}$ de comprimento, castanho escuro, com lenticelas, abrindo-se do ápice em direção à base (LORENZI et al. 2003).

Suas sementes são aladas e dispersas pelo vento, caracterizadas como ortodoxas e devem ser armazenadas em temperatura de $-18{ }^{\circ} \mathrm{C}$ ou em nitrogênio líquido para manter a viabilidade por períodos mais longos (SOUZA et al. 2010). A reprodução ocorre por meio de sementes, entretanto há investimentos em mudas clonais, principalmente pelo método de miniestaquia (SOUZA et al. 2009). TEIXEIRA (2001) afirma que as principais empresas florestais brasileiras usam a propagação vegetativa por miniestaquia para a produção comercial de mudas, o que consiste na utilização de brotações novas, coletadas em mudas propagadas vegetativamente e conduzidas em minijardim clonal.

A madeira do cedro-australiano é semelhante ao mogno brasileiro (Swietenia macrophylla) nas propriedades físicas e mecânicas. A madeira tem cor vermelho-clara que escurece com o tempo, é brilhante, tem peso médio, textura moderadamente grosseira, mas uniforme, grã direita a levemente revessa e boa trabalhabilidade. A madeira apresenta massa específica básica que varia entre 0,31 e 0,42 g/ $\mathrm{cm}^{3}$ (ZIECH 2008).

A espécie tem crescimento rápido e pela origem tropical, necessita de elevados índices de radiação solar para um desenvolvimento satisfatório, no entanto, ressalta-se que no estágio inicial o sombreamento favorece o seu estabelecimento e crescimento, característica de plantas do estágio sucessional secundário. É moderadamente tolerante à falta de água, mas altamente responsiva a quantidade de água disponibilizada durante o seu ciclo, com incrementos acentuados e rápidos (SOUZA et al. 2010).

A espécie foi introduzida no Brasil, onde encontrou condições edafoclimáticas favoráveis ao seu desenvolvimento. Apresenta bom crescimento em regiões de 500 a $1500 \mathrm{~m}$ de altitude e com regime pluviométrico de 800 a $1800 \mathrm{~mm} / \mathrm{ano}$, desenvolvese bem em plantios de regiões com $4000 \mathrm{~mm}$ de precipitação anual. É tolerante a geada leve de curta duração, sendo que a temperatura para o seu desenvolvimento fica em torno de 20 a $26{ }^{\circ} \mathrm{C}$, no entanto a espécie sobrevive a temperaturas mínimas absolutas pouco abaixo de $0{ }^{\circ} \mathrm{C}$. $\mathrm{O}$ cedro-australiano não suporta solos argilosos, compactados ou pobres, tendo preferência por solos calcários (PINHEIRO et al. 2003; 2006).

No Brasil, ZIECH (2008) ressalta que o cedroaustraliano se adaptou bem no Sul da Bahia e em toda região Sudeste, tendo destaque no Espírito Santo e Minas Gerais, com plantios em escala comercial bem desenvolvidos.

De acordo com MANGIALAVORI et al. (2003), o cedro-australiano é uma espécie promissora 
para plantios comerciais devido a qualidade de sua madeira, rápido crescimento e imunidade a broca de ponteiros (Hypsipyla grandella), que afeta os cedros nativos. FERREIRA et al. (2012) destacam que a espécie vem sendo introduzida no Brasil há quase três décadas e a cada dia atrai mais a atenção de produtores e ganha o seu espaço no mercado brasileiro, por ser uma alternativa lucrativa e que possui madeira semelhante ao cedro brasileiro (OLIVEIRA et al. 2008).

Vários espaçamentos têm sido utilizados para o plantio, como o $2 \times 2 \mathrm{~m}, 3 \times 2 \mathrm{~m}$ e com desbastes iniciados aos 2 anos nos plantios mais adensados e, posteriormente, nos demais. As mudas são plantadas no campo com cerca de 3 meses, em épocas chuvosas. Havendo possibilidade de fornecimento de água no período inicial, os plantios podem ser realizados em outras épocas do ano, sendo recomendada a aplicação de hidrogel, que consiste em polímeros hidroretentores naturais (derivados do amido) ou sintéticos (derivados do petróleo), que tem função de absorver e armazenar água na cova de plantio (MORAES 2001; SOUZA et al. 2010).

O cedro-australiano é uma espécie semiesciófila, suportando um sombreamento leve na fase juvenil, sendo esta uma vantagem para plantios consorciados, os quais são menos sucetíveis ao ataque de fungos e insetos do que em monoculturas (BRISTOW et al. 2005; PINHEIRO et al. 2006).

É exigente em nutrientes, em especial ao cálcio, o que torna necessário a adubação no plantio, conforme análises de solo. Os plantios mais desenvolvidos, segundo SOUZA et al. (2010), encontram-se em solos ricos em nutrientes, aluviais, com boa drenagem, profundos e eutróficos.

Não é recomendado o plantio em solos argilosos compactados e nem em solos arenosos pobres, a menos que esses solos sejam preparados para receber a cultura. Pela pouca tolerância a solos ácidos, é necessária a correção em casos de baixo valor de $\mathrm{pH}$. Solos rasos com algum impedimento físico, como rochas ou camadas adensadas, devem ser evitados, pois comprometem o estabelecimento e o crescimento da espécie (SOUZA et al. 2010).

O incremento médio anual da espécie tem potencial para atingir $30 \mathrm{~m}^{3} / \mathrm{ha} / \mathrm{ano}$, dependendo das condições de implantação, solo, clima, precipitação e tratos culturais adequados (VILELA \& STEHLING 2015).

O custo de manutenção do povoamento é baixo, sendo necessárias duas adubações de cobertura com nitrogênio e potássio, ao final do primeiro e do segundo ano, controle constante de formigas cortadeiras na área e monitoramento para detectar a presença de demais pragas e doenças. Os custos com a colheita e transporte são os mais altos de todo o processo, variando conforme a declividade do terreno e a fase da colheita - desbaste ou corte final (SOUZA et al. 2010).

Dados da empresa BELA VISTA FLORESTAL (2008) remetem a plantas com um ano de idade e três metros de altura em plantios no sudeste de Minas Gerais. No município de Venda Nova do Imigrante no Espírito Santo, observaram-se plantas com seis metros de altura e três anos de idade e outras com 10 metros de altura em seis anos de idade, mostrando a diferença entre os genótipos a serem selecionados.

O corte comercial do cedro-australiano ocorre, geralmente, aos 12 anos, mas pode variar de acordo com as características do povoamento e a finalidade da madeira. A produtividade média observada aos 10 anos é de $150 \mathrm{~m}^{3} \mathrm{ha}^{-1}$, para madeira serrada (SOUZA et al. 2010).

Em seu ambiente natural, a Toona ciliata tem seu desenvolvimento prejudicado pela praga Hypsipyla robusta, lepidóptero que constrói galerias no interior dos ramos, reduzindo o crescimento e perda da dominância apical (CUNNINGHAM \& FLOYD 2006).

BYGRAVE \& BYGRAVE (2005) garantem que ao ser cultivado no Brasil, o cedro- australiano não sofre ataque de sua praga natural, sendo mais vantajoso que o cedro brasileiro (Cedrella fissilis), devido ao fato de não sofrer ataque da praga Hypsipyla grandella, a qual afeta a gema apical de meliáceas brasileiras como o mogno (Swietenia macrophylla) e o cedro.

Outro problema, destacado por GONÇALVES \& OLIVEIRA (2006), para o cedro-australiano é o ataque do cupim de madeira seca (Cryptotermes brevis), o qual causa um desgaste superficial moderado na madeira, prejudicando a qualidade e o acabamento de móveis e outras peças.

Os plantios comerciais do cedro-australiano no Brasil são afetados, em sua maioria, conforme dados do CIF (2010), pelo ataque de pragas como o besouro serrador do gênero Oncideres sp., as formigas cortadeiras das espécies Atta sexdens rubropilosa e Atta laevigata e da planta parasita erva de passarinho (Struthantus flexicaulis). Essas pragas, 
tipicamente florestais, interferem no crescimento e desenvolvimento, principalmente, nos primeiros anos de idade.

O cedro-australiano apresenta uma ampla utilização, como por exemplo, na construção de mobílias de luxo e embarcações, na produção de compensados, laminados, ornamentos de interior, marcenaria, instrumentos musicais, caixas e engradados, entre outros usos (WORLD AGROFORESTRY CENTRE 2009). Também pode ser empregada para arborização em parques e jardins, sendo mais apropriada para regiões tropicais (LORENZI et al. 2003). A produção de madeira de Toona ciliata no Brasil vem sendo destinada para serrarias em função de sua elevada qualidade como grã reta e desenhos atrativos (RIBEIRO 2011).

\section{Khaya spp.}

Khaya spp. é conhecida popularmente como mogno africano, diversas espécies são cultivadas, dentre elas: $K$. ivorensis, $K$. senegalensis, $K$. anthotheca e $K$. grandifolia. É originária das regiões tropicais úmidas de baixa altitude, ocorrendo de 0 a $450 \mathrm{~m}$ de altitude, suporta inundações durante períodos de chuvas e é muito sensível a estiagem. O mogno africano é natural da África ocidental, da Costa do Marfim, Gana, Togo, Benim, Nigéria e sul de Camarões (ACAJOU D’AFRIQUE 1979).

No Brasil o mogno de origem africana vem se tornando uma espécie de grande importância na Região Amazônica, em virtude do seu alto valor econômico, facilidade de produção de mudas e rápido crescimento, promovendo a recuperação de áreas alteradas (GASPAROTTO et al. 2001; COUTO et al. 2004).

Essa espécie foi introduzida no Brasil, segundo COUTO et al. (2004), para a substituição do mogno brasileiro (Swietenia macrophylla), pois apresentou uma alta resistência à broca-do-ponteiro conhecido também como broca das meliáceas (Hypsipyla grandella Zeller), que é a principal praga do mogno nativo. Com a proibição da exploração e comercialização do mogno brasileiro no ano de 2000, ocorreu à busca de uma madeira que o substituísse, e o mogno africano apresentou-se como uma alternativa promissora.

Quando se compara o mogno africano e o brasileiro, percebe-se que esses não apresentam diferenças significativas, quanto ao fenotípico. Ressalta-se que a diferença expressiva, que faz a distinção entre os dois é a coloração, sendo que o mogno africano é avermelhado devido à concentração de antocianina do fluxo apical, e o brasileiro é mais esverdeado (FALESI \& BAENA 1999).

O mogno africano é uma planta heliófila, porém, tolerante à sombra durante a fase jovem. Quando se encontra em ambiente natural, frutifica duas vezes por ano, porém na região de Belém no Pará, verificou-se somente uma vez a florada. É uma árvore robusta com porte elevado que domina o dossel, sendo caducifólia nos climas áridos. O caule é retilíneo, sem ramificações até $30 \mathrm{~m}$ de altura, pode atingir diâmetro de até 3,5 metros e altura total de 70 metros (GROGAN et al. 2002).

O sistema radicular tabular é amplo, pode atingir até cinco metros de base. A casca é espessa e rugosa, possui resistência ao fogo e tem coloração marromavermelhada, as folhas são paripenadas, com pares de folíolos brilhantes e glabros, sua inflorescência é uma panícula e o fruto é constituído por uma cápsula acastanhada de 5 a $7 \mathrm{~cm}$ de diâmetro e ao abrir as cinco valvas, soltam cerca de 15 sementes achatadas e aladas (LAMPRECHT 1990; LAMB 1966; GROGAN et al. 2002).

A madeira da espécie é durável, de fácil trabalhabilidade e secagem, porém, possui difícil impregnação. $\mathrm{O}$ alburno tem coloração marrom amarelada e o cerne marrom avermelhada. Tem alto valor no mercado internacional, atinge o ponto de corte entre 15 a 20 anos. A espécie tem um crescimento inicial rápido e grande potencial para utilização em sistemas consorciados, sendo indicada pela Embrapa Amazônia Oriental, para plantios comerciais e sistemas agroflorestais e silvipastoris (FALESI \& BAENA 1999; FALESI \& GALEÃO 2004).

Apesar de ter rápido crescimento a Khaya ivorensis e Khaya anthotheca têm o fuste mais reto do que Khaya senegalensis, livre de ramificações até a uma maior altura, e demandam precipitações anuais acima de $1.200 \mathrm{~mm}$. Já a Khaya senegalensis, é mais resistente a seca, portanto, pode entortar mais, e tem ramificações mais cedo e em menor altura, é aconselhada para regiões com déficit hídrico muito acentuado, índice pluviométrico abaixo de $800 \mathrm{~mm}$ (PORTAL MUDAS NOBRES 2013).

No Brasil o mogno africano tem se mostrado bem adaptado em altitudes de 100 a 1.200 metros, com pluviosidade entre 1.200 e $2.400 \mathrm{~mm} / \mathrm{ano}$, sua distribuição ocorre de norte a sul, compreendendo os estados de Santa Catarina ao Pará (CERF 2013). 
A espécie tem seu crescimento favorecido em solos de terra firme, em regiões de clima tropical úmido ou subtropical. Pesquisas apontam que essa espécie se adapta bem a adubação orgânica, o esterco é uma ótima opção, no entanto, é imprescindível que o composto orgânico esteja bem curtido para não prejudicar o seu desenvolvimento. Com a adubação orgânica, o mogno africano alcança crescimento superior a 50\% no primeiro ano, comparado ao crescimento obtido sem adubação (PAINEL FLORESTAL 2013).

Dados do PAINEL FLORESTAL (2013) ressaltam que é importante avaliar as condições do solo, clima e do terreno, no plantio de mogno africano, em alguns cultivos adotam espaçamentos que variam de 4 x 4 m a 5 x $5 \mathrm{~m}$. O desbaste deve ser efetuado quando as copas se encontram, de tal forma que o espaçamento final seja de $8 \times 8 \mathrm{~m}$ ou $10 \times 10 \mathrm{~m}$.

O plantio pode ser feito através de sementes e mudas, a característica típica das sementes do mogno africano é seu formato, ligeiramente, achatado, fina e menor do que a do mogno brasileiro, cuja amêndoa lembra uma semente de abóbora. As sementes de Khaya ivorensis e Khaya senegalensis são semelhantes, entretanto, as mudas possuem coloração avermelhada no lançamento do broto apical devido à concentração de antocina, diferentemente do mogno brasileiro (ALBUQUERQUE 2011).

GOMES (2010) realizou um estudo, o qual faz parte de um projeto feito pelo Departamento de Engenharia Florestal de Viçosa, MG, com 10 hectares de plantio de mogno africano, em duas localidades, Igarapé, PA e outra no oeste do estado de Minas Gerais. As covas tiveram dimensões de $60 \mathrm{~cm}$ x 60 $\mathrm{cm} \times 60 \mathrm{~cm}$, o preparo do solo foi realizado com base na análise dos laudos de solo da região, o qual constituiu num composto de duas pás de esterco de curral curtido, terra da superfície de 0 a $20 \mathrm{~cm}$ de solo, com mais $1 \mathrm{~kg}$ de calcário dolomítico. $\mathrm{O}$ espaçamento foi de $5 \times 5 \mathrm{~m}$ sendo que as mudas tiveram altura de $50 \mathrm{~cm}$. Com 30 dias as plantas receberam a primeira adubação química (NPK 10-28-20) em $10 \mathrm{~cm}$ de profundidade sendo $120 \mathrm{~g}$ por planta, o procedimento foi repetido em 60, 90 e 120 dias.

O segundo ano iniciou-se em outubro (períodos de chuvas), onde foram colocados $120 \mathrm{~g}$ de adubo por planta, 30 dias após mais $180 \mathrm{~g}$ de adubo, e aos 60 dias adicionou-se $1 \mathrm{~kg}$ de esterco de curral e 60 $\mathrm{g}$ de adubo por furo. No terceiro ano repetiu-se a adubação, sendo esta em menores quantidades. Houve acompanhamento daflorestae do seu desenvolvimento.
Em períodos chuvosos as plantas foram mantidas coroadas para prevenir o encharcamento das raízes e ação dos fungos, e nos períodos de estiagem às plantas foram mantidas protegidas pela cobertura morta, para assegurar a umidade, e manter o processo de ação biológica promovida pelos microrganismos.

Foram obtidos bons resultados com os plantios no norte do Pará, a rentabilidade deu-se após o oitavo ano, mostrando-se uma cultura economicamente viável. Poucas pragas têm atacado os plantios de mogno africano, no entanto, é necessário que haja a prevenção da incidência de insetos e fungos que podem prejudicar as árvores.

Dentre os principais insetos destacam-se as abelhas negras, conhecidas como irapuá ou abelha cachorro (Trigona spp.), estas atacam severamente a porção apical de brotações novas, provocando a queda dos folíolos e com isso ocorre a queda das folhas, sendo destas consumidas a parte fibrosa e a resina para construção dos ninhos. $\mathrm{O}$ ataque resulta no atrofiamento das brotações, ocasionado ramificações no tronco (MENDES et al. 1979).

Outra praga associada à espécie, citada por ALBUQUERQUE (2011), é a broca das meliáceas (Hypsipila grandella). Esta é a principal praga que limita o crescimento dos plantios de mognos, pode ocorrer o ano todo e atacar mudas em viveiros, plantios jovens e árvores adultas, causando morte dos ponteiros, ramificação excessiva e destruição na semente e no fruto. $\mathrm{O}$ ataque de mudas ainda no período de viveiro pode ocasionar bifurcações e atraso no desenvolvimento causando até a morte.

Além disso, quando as mudas estão à campo, após a implantação o ataque é dirigido aos ponteiros que exsudam goma e morrem, o mesmo acontece quando atacam outras regiões, a planta reage com brotações laterais, as quais também são atacadas, já no fruto o inseto destrói a semente (ALBUQUERQUE 2011). O ataque ocorre com maior intensidade no período das chuvas, entre seis meses e três anos de idade, devido às brotações vigorosas das plantas e por se tratar do período em que será formado o fuste comercial de seis metros de altura (TROPICAL FLORA 2009).

O controle da praga é realizado através de controle químico (viáveis na fase de viveiro), e também por controle cultural, através da poda fitossanitária, dependendo da intensidade de ataque, a fim de combinar diferentes métodos de controle de ataque de $H$. grandella e minimizar os danos e 
os prejuízos monetários gerados (ALBUQUERQUE 2011).

O cancro do córtex ou cancro da casca é uma doença que, conforme afirmou ALBUQUERQUE (2011) é comum tanto em Khaya ivorensis quanto em Khaya senegalensis, mas em nenhum dos dois geram danos econômicos, apenas estéticos. O controle desta doença é bem simples e barato, o qual baseia-se na pulverização ou pincelamento sobre as lesões com produtos como Hipoclorito de Sódio a 2,5\% (água sanitária), calda bordalesa ou fungicidas a base de cobre.

Além disso, podem ocorrer nos indivíduos da espécie, manchas areoladas, que são causadas por um fungo conhecido como Thanatephorus cucumeris, presente em viveiros e áreas de plantios definitivos de mogno africano nos Estados do Amazonas e Pará, causa lesões nas folhas maduras com manchas de coloração marrom - clara e queda das folhas jovens que apresentam lesões marrons circuladas por uma cor púrpura. Esse ataque causa desfolhamentos de plantas com cerca de $7 \mathrm{~m}$ de altura, podendo reduzir o crescimento do mogno africano, desde que as condições favoráveis à infecção ocorram durante longos períodos.

A madeira do mogno africano é valorizada para carpintaria, marcenaria, móveis, construção naval e lâminas decorativas. É apropriada para a fabricação de pisos, acabamentos interiores, corpos de veículo, brinquedos, dormentes, tornearia e celulose (LAMPRECHT 1990).

A casca e as folhas das árvores da espécie possuem propriedades medicinais. A madeira tem boas propriedades de colagem, apresentando densidade básica de $0,51 \mathrm{~g} / \mathrm{cm}^{3}$. O cerne é resistente à impregnação e o alburno moderadamente resistente (ALBUQUERQUE 2011).

\section{Cordia americana (1.) Gottshling \& J.e.Mill.}

Cordia americana pertence à família Boraginaceae e está no grupo das secundárias iniciais a tardias. Há predominância de sua ocorrência na Floresta Estacional Semidecidual, Floresta de Araucária e Floresta Estacional Decidual, englobando os estados de São Paulo, Mato Grosso, Mato Grosso do Sul, Paraná, Santa Catarina e Rio Grande do Sul. É uma espécie que floresce, em suas áreas de ocorrência, entre os meses de julho a novembro, apresenta crescimento lento a moderado, nas capoeiras formam associações quase puras, demonstrando um crescimento rápido (CARVALHO 2003).

A espécie possui grande porte, segundo CARVALHO (2004), com altura entre 10 a $25 \mathrm{~m}$, com tronco geralmente tortuoso e irregular de 70 a $80 \mathrm{~cm}$ de diâmetro. É popularmente conhecida no país como apé-branco, guajubira, guaraiúva e pau-d'arco, nos estados de São Paulo, Mato Grosso do Sul, Paraná, Santa Catarina e Rio Grande do Sul, também é chamada de goarapovira, guaiabi, guaiabira, guaiaibira, guaibi, guaijibira, guaiuíra, guaiuvira e guajuvira.

Cordia americana, conforme CARVALHO (2004), é uma espécie de fácil visualização em campo, com folhas de margens serralhadas da parte central até a extremidade, com característica de ser semidecídua, hermafrodita e com dispersão dos frutos e sementes por anemocoria e autocoria (barocoria). Sua germinação é epígea, com início entre 12 a 78 dias após a semeadura, seu poder germinativo é em média de $80 \%$, podendo atingir até $100 \%$, as sementes não apresentam dormência. As mudas atingem porte apropriado para plantio, cerca de quatro meses após a semeadura. Outra alternativa para a produção de mudas da espécie se dá pela propagação vegetativa através de estacas de galhos.

Sendo uma espécie semi-heliófila, ela tolera sombreamento de baixa a média intensidade na fase juvenil, além de ser tolerante a baixas temperaturas, onde na idade adulta podem admitir temperaturas mínimas de até $-11^{\circ} \mathrm{C}$. O crescimento da espécie ocorre melhor em solos de boa fertilidade química, com propriedades físicas adequadas, bem drenados e com textura de areno-argilosa a argilosa, entretanto devem ser evitados os solos hidromórficos (CARVALHO (2004).

Desenvolve-se bem em locais com precipitação média anual entre 1000 a $2300 \mathrm{~mm}$. As chuvas podem ser bem distribuídas durante o ano ou periódicas (CARVALHO 2003). A temperatura é variável em todos os estados de ocorrência. Quanto ao clima (KÖEPPEN), pode ser encontrada em três tipos principais, sendo: subtropical úmido $(\mathrm{Cfa})$, temperado úmido $(\mathrm{Cfb})$ e subtropical de altitude (Cwa e $\mathrm{Cwb}$ ).

RODRIGUES et al. (2007) em um estudo realizado com agricultores que cultivavam espécies arbóreas nativas na Serra dos Tapes, RS, verificaram que Cordia americana está associada ao maior número de utilidades, tanto para a construção civil, onde é utilizada como esteio e na confecção das linhas da estrutura, como também na confecção de 
cabos das mais diversas ferramentas, sendo que com a madeira também se faz jugo, cheda, armação de carro, cambotas, rodas de carreta, arado, mangual e dormentes.

Por ser uma espécie nativa, a guajuvira deve ser plantada em espaçamentos maiores para melhor desenvolvimento e qualidade da madeira. Experimentos instalados no sul do Brasil com espaçamentos variáveis, sendo $3 \times 3 ; 3 \times 2 ; 4 \times 4 ; 4$ × 3 $\mathrm{m}$, os quais apresentaram boas taxas de sobrevivência e crescimento, principalmente nos espaçamentos maiores (CARVALHO 2003). Antes do plantio recomenda-se fazer análise do solo para verificar a necessidade de adubação da área.

CARVALHO (2003) salientou que as principais formas de produção de mudas desta espécie, ocorrem a partir da germinação das sementes e da propagação por estaca de galhos. Para a produção por sementes recomenda-se realizar a semeadura em sementeiras. Após 2 a 3 semanas devem ser repicadas as plântulas para tubetes ou sacos de polietileno, a partir do 4 meses após a semeadura as mudas já adquirem porte recomendado para o plantio, um ano após o plantio é necessário realizar irrigação diária.

Esta espécie apresenta crescimento lento a moderado, sendo bastante tolerante a geadas. Nas capoeiras, se desenvolve normalmente, formando associações quase puras, onde apresenta crescimento relativamente rápido, sendo uma árvore longeva. A madeira é de cor escura, densa $\left(0,75\right.$ a 0,90 g. $\left.\mathrm{cm}^{3}\right)$, pesada, o que pode dificultar a trabalhabilidade, entretanto, apresenta uma boa resistência ao apodrecimento e ataque de insetos, o que viabiliza sua utilização (FRANCK FILHO 2005).

Cordia americana não possui uma desrama natural satisfatória, por isso necessita da aplicação de tratos silviculturais para conduzir melhor seu desenvolvimento, como a realização de podas de formação e poda de limpeza para retirada de galhos, essas práticas beneficiam na melhora da qualidade do fuste intensificando seu crescimento, de forma a otimizar o aproveitamento de sua madeira (CARVALHO 2003).

É indicada para plantios em reflorestamentos puros, mistos e na vegetação secundária, aos 11 anos de idade chega a produzir $8 \mathrm{~m}^{3} \mathrm{ha}^{-1}$, após o corte ocorre rebrota da touça. Na região sul do Brasil à espécie vem sendo utilizada em sistemas agroflorestais, no sombreamento de pastagens para o gado (NAVARINI et al. 2009).
Estudos realizados em plantios nas cidades de Santa Helena, Cianorte e Laranjeiras do Sul, relataram o ataque de uma praga, o serrador Oncideres dejeani (Coleoptera: Cerambycidae) que causou danos severos, comprometendo o crescimento em altura das plantas. C. americana também é muito atacada por erva-de-passarinho (Phoradendron linearifolium), que é uma planta hemi-parasita (CARVALHO 2003).

A madeira de guajuvira, segundo CARVALHO (2003), é indicada para construção civil, em vigas, ripas, caibros, batentes de portas e janelas, tacos e tábuas para assoalhos. Em obras externas são indicada para postes, mourões, estacas, dormentes e cruzetas; cabos de ferramentas, peças torneadas e carroçarias; móveis de luxo e folhas faqueadas decorativas. A madeira apresenta boa elasticidade e flexibilidade, recomendada para a fabricação de peças curvadas.

A guajuvira pode ser utilizada ainda no paisagismo e na arborização de parques, assim como, para energia, celulose e papel. As flores são melíferas e as folhas apresentam grande importância medicinal (FRANCO \& FONTANA 2001; CARVALHO 2003). A guajuvira apresenta-se cada vez mais como uma espécie promissora não só para plantios comerciais, mas também pode ser utilizada na recuperação de ambientes degradados.

\section{Aspidosperma polyneuron Müll. Arg.}

Aspidosperma polyneuron é uma espécie pertencente à família Apocynaceae, sendo uma árvore com característica secundária tardia ou clímax tolerante à sombra, perenifólia, presente geralmente no interior de florestas primárias densas. Em média sua altura pode variar de 20 a $30 \mathrm{~m}$ e seu diâmetro a altura do peito (DAP) de 50 a $100 \mathrm{~cm}$, podendo atingir até $50 \mathrm{~m}$ de altura e $390 \mathrm{~cm}$ de DAP, em idade adulta (FONSECA 2001; LORENZI et al. 2003; CARVALHO 2004).

A espécie, conforme CARVALHO (2004), é característica da Floresta Estacional Semidecidual, na formação montana e submontana. A sua ocorrência natural se dá, principalmente, nas regiões Sul, Sudeste e Centro-Oeste, é popularmente conhecida como peroba-rosa, peroba-paulista, peroba-rajada, perobado-rio, perobinha ou perova.

É uma espécie que se ramifica somente na parte superior do tronco, e possui uma copa alta, densa, com ramos trifurcados, o que facilita sua identificação no meio das demais árvores. Além disso, a casca pode apresentar uma espessura de até $50 \mathrm{~mm}$, 
externamente a casca é cinzenta a castanho-grisácea, áspera, profundamente fissurada longitudinalmente, e internamente, ao ser raspada, apresenta um róseo muito intenso por dentro e a parte viva amarelada. Suas folhas são simples, alternas, variáveis quanto à forma, com ápice arredondado e margem inteira (CARVALHO 2004).

Aspidosperma polyneuron é uma planta hermafrodita, possui flores pequenas e numerosas, a floração ocorre entre os meses de setembro a janeiro, nos diferentes estados de ocorrência natural, porém, não floresce anualmente, produz uma grande quantidade de sementes apenas em intervalos de 2 a 4 anos (LORENZI 1992). O fruto, conforme CARVALHO (2004), é um folículo deiscente, geralmente achatado e semilenhoso, coberto por lenticelas com 2 a 5 sementes por fruto, a frutificação ocorre entre maio a setembro, as sementes não possuem dormência e tem comportamento recalcitrante, a formação da muda se dá a partir de 9 meses após a semeadura.

A espécie tem característica semi-heliófila e na fase juvenil necessita de sombreamento, porém, após seu desenvolvimento se torna tolerante a luz, CARVALHO (2004) ainda destaca que a planta apresenta resistência a baixas temperaturas, sendo que, em florestas naturais, árvores adultas suportam temperaturas mínimas de até $-6^{\circ} \mathrm{C}$.

De acordo com KAGEYAMA \& CASTRO (1989) em função de sua exigência ecológica, necessita de uma espécie estimuladora como vizinha para ter seu crescimento e tronco favorecidos. Além disso, é considerada uma espécie de grande importância em plantios mistos de recuperação de áreas degradadas. Em plantios densos, a espécie apresenta desrama natural e boa cicatrização, entretanto, em plantios com espaçamento maior há necessidade de intervenções para que a desrama seja eficaz, devido a bifurcações localizadas próximo ao solo.

A madeira de Aspidosperma polyneuron apresenta densidade média variando de 790 a 898 $\mathrm{kg} \mathrm{m}^{-3}$, pouca resistência ao ataque de organismos xilófagos e baixa permeabilidade às soluções preservantes, em tratamentos sob pressão. A utilização de sua madeira é para diversas finalidades, dentre elas, para madeira roliça e serrada na indústria de móveis e construção civil, para energia possui boa qualidade, com poder calorífico de $4.750 \mathrm{kcal} / \mathrm{kg}$, entretanto, a espécie é inadequada para celulose e papel (CARVALHO 2004).

PINAZO et al. (2009) destacam que
Aspidosperma polyneuron é uma das espécies das florestas paranaenses que apresentam alto valor agregado em sua madeira, e devido a isso sofreu com a intensa exploração, o que ocasionou a proibição de seu corte. Frente a isso, SATO et al. (2008) afirmaram a importância da manutenção dessa espécie, principalmente, relacionado com programas de conservação e melhoramento, subsidiando alternativas de plantios para exploração econômica e diminuindo a pressão sobre populações nativas.

Aspidosperma polyneuron é classificada, segundo a lista da IUCN (2003), na categoria "em perigo", ou seja, em perigo de extinção e cuja sobrevivência é improvável se os fatores causais continuarem operando. Na lista oficial de espécies da flora ameaçadas de extinção no Paraná (IAP 2008), a espécie é classificada como categoria "rara", apresentam poucos indivíduos tanto em vasta área quanto em pequena, ou revelam-se endêmicos.

A espécie é inadequada para plantio puro a pleno sol, mesmo em solo de boa fertilidade química, devido a isso, indica-se plantio misto, associado com espécies pioneiras. Há resultados bem-sucedidos de plantio de Aspidosperma polyneuron com grevílea (Grevillea robusta), calabura (Muntigia calabura), e outras pioneiras (MORA et al. 1980; GURGEL FILHO et al. 1982) . Nesses cultivos mistos as plantas da espécie, apresentam maior crescimento em relação aos plantios homogêneos.

A utilização de sua madeira é para diversas finalidades, dentre elas, CARVALHO (2004) aponta a madeira roliça e serrada na indústria de móveis e construção civil, a madeira de Aspidosperma polyneuron, por ser de resistência mecânica e retratibilidade médias, era muito usada na indústria de móveis e indicada, principalmente, em construção civil, para caibros, ripas, forro, marcos de portas e janelas, venezianas, portões, rodapés, molduras, tábuas; construção naval e canoas (o tronco todo), vigamentos, esquadrias, obras externas, construção de vagões, móveis escolares, carrocerias, cabos de ferramentas, produção de folhas faqueadas e parquê. Além disso, é de uso quase irrestrito em carpintaria, na fabricação, entre outros objetos, de vigas, escadas, tacos e de móveis pesados.

\section{CONCLUSÃO}

O cultivo econômico de Toona ciliata representa importante alternativa para o fornecimento 
de madeira de qualidade, contribuindo com a geração de mais um aporte econômico para o país e com a redução da velocidade de exploração das matas nativas ainda existentes.

Khaya spp. tem uma madeira de grande importância, pois vêm substituir o mogno brasileiro que foi muito utilizado no passado, porém essa espécie traz consigo grandes qualidades que vêm viabilizar economicamente e ecologicamente seu plantio.

Entretanto as espécies de Cordia americana e Aspidosperma polyneuron mostram-se com grande potencial ainda a ser explorado, enfatizando a importância da realização de estudos sobre seu uso adequado de maneira a atender as exigências de sustentabilidade.

\section{REFERÊNCIAS}

ALBUQUERQUE CP. 2011. Levantamento bibliográfico sobre mogno africano. Conflor, FCA. UNESP. 24p. ACAJOU D'AFRIQUE, 1979 apud CONDE, 2006. In SILVA, BTB. 2010. Avaliação da usinagem e caracterização das propriedades físicas da madeira de Mogno Africano (Khaya ivorensis A. Chev.). Disponível em: http://www. if.ufrrj.br/inst/monografia/2009II/Bruno.pdf. Acesso em: 15 jan. 2014.

BELA VISTA FLORESTAL. 2008. Blog cedro australiano: informações atualizadas sobre o cultivo desta espécie. Disponível em: http://www.belavistaflorestal.com.br. Acesso em: 25 jan. 2014.

BYGRAVE FL \& BYGRAVE PL. 2005. Growing Australian red cedar and other Meliaceae species in plantation. Canberra: Rural industries. 60p.

BRISTOW M et al. 2005. Growing rainforest timber trees: a farm forestry manual for north Queensland. Barton: Rirdc. 77 p.

CAIÇARA EMPREENDIMENTOS RURAIS E FLORESTAIS - CERF. 2013. Mogno Africano - chama de ouro verde. Disponível em: http:// www.mudasmognoafricano.com.br/site/arquivos/ mognoafricano.pdf. Acesso em: 20 jan. 2014.

CARVALHO PER. 2003. Espécies Arbóreas Brasileiras. Colombo: Embrapa Florestas. 1039p.

CARVALHO PER. 2004. Guajuvira - Patagonula americana. Colombo: Embrapa Florestas. 10p. (Circular Técnica 97).

CENTRO DE INTELIGÊNCIA EM FLORESTAS - CIF. 2010. Cedro australiano. Disponível em: http://www. ciflorestas.com.br/texto.php? $\mathrm{p}=$ cedro_australiano. Acesso em: 18 de jan. 2014.

COUTO JMF et al. 2004. Desinfestação e germinação in vitro de sementes de mogno (Swietenia macrophylla King). Revista Árvore 28: 633-642.

CUNNINGHAM SA \& FLOYD RB. 2006. Toona ciliata that suffer frequent height-reducing herbivore damage by a shoot-boring moth (Hypsipyla robusta) are taller. Forest Ecology and Management 225: 400-403.

FERREIRA DA et al. 2012. Influência da posição das miniestacas na qualidade de mudas de cedro australiano e no seu desempenho inicial no pós-plantio. Ciência Florestal 22: 715-723.

FRANCK FILHO FH. 2005. Seleção de espécies arbóreas nativas da região sul do Brasil para reflorestamento e emprego na arquitetura e no design. Dissertação (Mestrado em Engenharia). Porto Alegre: UFRGS. 140p.

FRANCO IJ \& FONTANA VL. 2001. Ervas e Plantas - A medicina dos simples. 6.ed. Erechim: Edelbra. 207p.

GARRIDO MAO. 1981. Caracteres silviculturais e conteúdo de nutrientes no folhedo de alguns povoamentos puros e mistos de espécies nativas. Dissertação (Mestrado em Engenharia Florestal). Piracicaba: ESALQ. 105p.

GASPAROTTO L et al. 2001. Mancha areolada causada por Thanatephorus cucumeris em mogno-africano. Fitopatologia Brasileira 26: 660-661.

GONÇALVES FG \& OLIVEIRA JTS. 2006. Resistência ao ataque de cupim-de-madeira-seca (Cryptotermes brevis) em seis espécies florestais. Cerne. 4p. (Nota Técnica 1).

FALESI IC \& BAENA ARC. 1999. Mogno-africano (Khaya ivorensis A. Chev.) em sistema silvipastoril com leguminosa e revestimento natural do solo. Belém: Embrapa Amazônia Oriental. 52p. (Documentos, 4).

FALESI IC \& GALEÃO RR. 2004. Recuperação de áreas antropizadas da mesorregião do nordeste paraense através de sistemas agroflorestais. Belém: Emater. Disponível em: $\quad$ http://ainfo.cnptia.embrapa.br/digital/bitstream/ item/100166/1/0915.pdf. Acesso em: 15 de jan 2014.

FONSECA MG. 2001. Aspectos demográficos de Aspidosperma polyneuron Muell. Arg. (Apocynaceae) em dois fragmentos de floresta semidecídua no município de Campinas, SP. Dissertação (Mestrado em Biologia Vegetal). Campinas: UNICAMP. 115p.

GOMES DM. 2010. Análise de viabilidade técnica econômico-financeira para implantação da cultura do mogno africano (Khaya ivorensis A. Chev.) na região no oeste de Minas Gerais. Monografia (Especialização em Gestão Florestal). Curitiba: UFPR. 70p.

GROGAN J et al. 2002. Mogno na Amazônia Brasileira: Ecologia e Perspectivas de Manejo. Belém: Imazon. Disponível em: http://imazon.org.br/publicacoes/mognona-amazonia-brasileira-ecologia-e-perspectivas-demanejo/. Acesso em: 20 jan. 2014.

GURGEL FILHO AO et al. 1982. Silvicultura de essências indígenas sob povoamentos homóclitos coetâneos experimentais I- Araribá amarelo (Centrolobium tomentosum Benth.). In: Congresso Nacional sobre essências nativas. Resumos... São Paulo: Instituto Florestal. p.841-846.

IAP - INSTITUTO AMBIENTAL DO PARANÁ. 2008. Lista oficial de espécies da flora em extinção. 11p. 
Disponível em: ttp://www.iap.pr.gov.br/arquivos/File/ Atividades/POP5_LISTA_OFICIAL_ESPECIES

EXTINCAO.pdf. Acesso em: 21 dez. 2014.

IUCN - UNIÃO INTERNACIONAL PARA A CONSERVAÇÃO DA NATUREZA E DOS RECURSOS NATURAIS. 2003. Lista da flora ameaçada. 15p. Disponível em: http://www.biodiversitas.org.br/cepf/edital/flora_iucn. pdf. Acesso em: 23 ago. 2015.

KAGEYAMA PY \& CASTRO CFA. 1989. Sucessão secundária, estrutura genética e plantações de espécies arbóreas nativas. Piracicaba: IPEF. Disponível em: http:// www.ipef.br/publicacoes/scientia/nr41-42/cap11.pdf. Acesso em: 10 jan. 2014.

LAMB FB. 1966. Mahogany of tropical America: its ecology and management. The University of Michigan Press, Ann Arbor, MI. 220p.

LAMPRECHT H. 1990. Silvicultura nos trópicos: ecossistemas florestais e respectivas espécies arbóreas: possibilidades e métodos de aproveitamento sustentado. Eschborn: GTZ. 343p.

LORENZI H. 1992. Árvores brasileiras: manual de identificação e cultivo de plantas arbóreas nativas do Brasil. Nova Odessa: Instituto Plantarum. 353p.

LORENZI H et al. 2003. Árvores exóticas no Brasil: madeireiras, ornamentais e aromáticas. 1.ed. Nova Odessa: Instituto Plantarum. 384p.

MANGIALAVORI A et al. 2003. Growth measurements in commercial plantations of Australian red Redar (Toona ciliata var. australis) in Salta province, Argentina. SAGPyA Forestal, 26: 2-6.

MENDES ACB et al. 1979. Ao cacaueiro na Amazônia brasileira. Comissão Executiva do Plano da Lavoura Cacaueira. Departamento Especial da Amazônia. 13p. (Comunicado Técnico Especial).

MORA AL et al. 1980. Espécie florestal para alimentação de fauna silvestre. Piracicaba: IPEF. 4p. (Circular Técnica 93).

MORAES O. 2001. Efeito do uso de polímero hidroretentor no solo sobre o intervalo de irrigação na cultura da alface (Lactuca sativa L.). Tese (Doutorado em Agronomia). Piracicaba: ESALQ. 73f.

NAVARINI FC et al. 2009. Conforto térmico de bovinos da raça nelore a pasto sob diferentes condições de sombreamento e a pleno sol. Engenharia Agrícola 29: 508517.

OLIVEIRA JR. et al. 2008. Análise dos teores de clorofila e carotenóides como indicadores de fitotoxicidade de herbicidas em Toona ciliata var. australis. In: I Jornada Científica e VI FIPA do CEFET Bambuí. Anais... Bambuí/ MG. p.15.

PINHEIRO AL et al. 2003. Cultura do Cedro australiano para produção de madeira serrada. Viçosa: UFV, 42p.

PINHEIRO AL et al. 2006. Cedro Australiano: cultivo e utilização (Toona ciliata M. Roem. Var. australis (F. Muell) Bahadur). Viçosa: UFV. 42p.
PORTALMUDAS NOBRES. 2013. Origem e características do Mogno Africano. Disponível em: mudasnobres.com.br/ origem-do-mogno-africano. Acesso em 21 jan. 2014.

PAINEL FLORESTAL. 2013. Mogno africano - espécie importada ganha espaço entre os agricultores. Disponível em: http://www.painelflorestal.com.br/noticias/madeiranobre/mogno-africano-especie-importada-ganha-espacoentre-os-agricultores. Acesso em: 02 fev. 2014.

PINAZO M et al. 2009. Patrón Espacial de la Regeneración de Aspidosperma polyneuron Müll. Arg. en un bosque sometido a aprovechamiento selectivo en el norte de la provincia de Misiones. Ciência Florestal 19: 237-245.

RIBEIRO MX. 2011. Resistência de painéis aglomerados a cupins de madeira seca (Cryptotermes brevis). Dissertação (Mestrado em Ciência e Tecnologia da Madeira). Lavras: UFLA. $92 \mathrm{f}$.

RODRIGUES WF et al. 2007. Espécies arbóreas da Serra dos Tapes: um resgate etnobotânico. EMBRAPA. Pelotas, 68p. (Documentos 190).

SATO AS et al. 2008. Crescimento e sobrevivência de duas procedências de Aspidosperma polyneuron em plantios experimentais em Bauru, SP. Revista do Instituto Florestal 20: 23-32.

SOUZA JCAV et al. 2009. Propagação vegetativa de cedroaustraliano (Toona ciliata M. Roemer) por miniestaquia. Revista Árvore 33: 205-213.

SOUZA JCAV et al. 2010. Cedro australiano (Toona ciliata). Niterói: Programa Rio Rural, 12p. (Manual Técnico 21).

STYLES BT 1972. The flower biology of the Meliaceae and its bearing on tree breeding. Silvae Genetica 21: 175182.

TEIXEIRADA. 2001. Promoção de enraizamento e indução de resistência sistêmica à ferrugem (Puccinia psidii) e à mancha de Cylindrocladium candelabrum mediadas por rizobactérias em Eucalyptus spp. Tese (Doutorado em Fitopatologia). Viçosa: UFV, 67p.

TROPICAL FLORA. 2009. Reflorestamento com mogno africano. Disponível em: http://www.tropicalflora.com. br/tropicalflora/pt/index.php?gclid. Acesso em: 22 de fev. 2015.

VILELA ES \& STEHLING EC. 2015. Recomendações de plantio para o cedro australiano. Versão Mudas Clonais 3.0. Bela Vista Florestal: Campo Belo. 20p.

WORLD AGROFORESTRY CENTRE. 2009. AgroForestryTree Database. A Tree Species Reference and Selection Guide. Disponível em: http://www. worldagroforestrycentre.org/sea/Products/AFDbases/AF/ asp/BotanicSearch.asp. Acesso em: 15 jan. 2014.

ZIECH RQS. 2008. Características tecnológicas da madeira de cedro-australiano (Toona ciliata $\mathrm{M}$. Roem) produzida no sul do Estado de Minas Gerais. Dissertação (Mestrado em Ciência e Tecnologia da Madeira). Lavras: UFLA. 91p. 